\title{
11 $\beta$-Hydroxysteroid dehydrogenase Type 1: genetic polymorphisms are associated with Type 2 diabetes in Pima Indians independently of obesity and expression in adipocyte and muscle
}

\author{
S. Nair ${ }^{1}$ Y. H. Lee ${ }^{1}$ R. S. Lindsay ${ }^{2}$ B. R. Walker ${ }^{3}$ P. A. Tataranni ${ }^{1}$ C. Bogardus ${ }^{1}$ L. J. Baier ${ }^{1}$ P. A. Permana ${ }^{4}$ \\ ${ }^{1}$ National Institute of Diabetes and Digestive and Kidney Diseases, National Institutes of Health, Phoenix, Arizona, USA \\ 2 Division of Cardiovascular and Medical Sciences, Gardiner Institute, Glasgow, Scotland, UK \\ ${ }^{3}$ University of Edinburgh, Endocrinology Unit, Western General Hospital, Edinburgh, Scotland, UK \\ ${ }^{4}$ Carl T. Hayden VA Medical Center, Phoenix, Arizona, USA
}

\section{Abstract}

Aims/hypothesis. The enzyme 11ß-hydroxysteroid dehydrogenase type 1 (11ß-HSD1) modulates tissuespecific glucocorticoid concentrations by generating active cortisol. We have shown that adipose tissue $11 \beta$-HSD1 mRNA levels were associated with adiposity and insulinaemia. Here we conducted further expression and genetic association studies in Pima Indians.

Methods. The 11 $\beta$-HSD1 mRNA concentrations were measured in abdominal subcutaneous adipocytes $(n=61)$ and skeletal muscle tissues $(n=64)$. Single nucleotide polymorphisms in the HSD11B1 gene were genotyped in a larger group of full-blooded Pima Indians.

Results. Two representative SNPs (SNP1, $n=706$; SNP5, $n=839)$ were associated with Type 2 diabetes mellitus $(p=0.01)$, although neither SNP was associated with obesity. Among subjects with normal glucose tolerance, SNP1 $(n=127)$ and SNP5 $(n=159)$ were associated with insulin-mediated glucose uptake rates ( $p=0.03$ and $p=0.04$ ), and SNP1 was further associated with fasting, 30-min, and 2-h plasma insulin concen- trations ( $p=0.002, p=0.002$ and $p=0.03$ ). Adipocyte $11 \beta$-HSD1 mRNA concentrations were correlated positively with adiposity and insulinaemia, and were additionally negatively correlated with insulin-mediated glucose uptake rates; nevertheless, the adipocyte $11 \beta$-HSD1 expression did not correlate with genotypes of the donors. The muscle 11 $\beta$-HSD1 mRNA concentrations did not correlate with any anthropometric or metabolic variables.

Conclusions/interpretation. We confirmed that adipocyte $11 \beta$-HSD1 mRNA concentrations were associated with adiposity, and showed that genetic variations in the HSD11B1 gene were associated with Type 2 diabetes mellitus, plasma insulin concentrations and insulin action, independent of obesity. The variable adipose expression might not be a primary consequence of these HSD11B1 SNPs. Therefore, it is possible that the $H S D 11 B 1$ gene is under tissue-specific regulation, and has tissue-specific consequences.

Keywords Adipocyte - Genetic polymorphisms · Insulinaemia $\cdot 11 \beta$-Hydroxysteroid dehydrogenase type $1 \cdot$ Obesity - Type 2 diabetes mellitus
Received: 6 January 2004 / Accepted: 10 March 2004

Published online: 20 May 2004

(C) Springer-Verlag 2004

P. A. Permana (๘)

Carl T. Hayden VA Medical Center, Phoenix, Arizona, USA

E-mail: paska.permana@med.va.gov

Tel.: +1-602-2775551 ext. 6085

Fax: +1-602-2122047

Abbreviations: 11 $\beta$-HSD1, 11 -Hydroxysteroid dehydrogenase type $1 \cdot$ SNPs, single nucleotide polymorphisms

\section{Introduction}

The enzyme $11 \beta$-hydroxysteroid dehydrogenase type 1 (11 $\beta$-HSD1) converts inactive cortisone to active cortisol and is expressed in many tissues including liver, adipose tissue, muscle, pancreas, gonads and brain [1, $2,3,4]$. Changes in local concentrations of glucocorticoids due to $11 \beta$-HSD1 activity have been implicated in obesity and its metabolic consequences including insulin resistance and Type 2 diabetes mellitus [5].

Adipose tissue seems to be an important primary site for $11 \beta$-HSD1 action in obesity. The adipose $11 \beta$ - 
HSD1 mRNA and/or activity is positively correlated with obesity in at least four different populations $[6,7$, $8,9,10,11]$, though not all [12]. Transgenic mice overexpressing 11 $\beta$-HSD1 in adipose tissue develop hyperphagia, visceral obesity, hyperglycaemia, hyperinsulinaemia, glucose intolerance, insulin resistance and hyperlipidaemia [13]. Consistent with these studies, we recently showed that increased $11 \beta-H S D 1$ activity and mRNA levels in whole subcutaneous adipose tissue were associated with adiposity and hyperinsulinaemia in 19 Pima Indian subjects and 12 Caucasians [9].

Although many studies have focused on the role of $11 \beta$-HSD1 in the expansion of adipose tissue, modulation of $11 \beta$-HSD1 activity has an effect on multiple target tissues which may promote insulin resistance independently of obesity. For example, in non-obese glucose-intolerant patients, adipose $11 \beta$-HSD1 activity is not increased and hepatic 11 $\beta$-HSD1 activity is maintained [14] compared with the down-regulation of he-

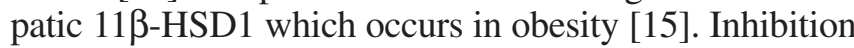
of 11ß-HSD1 with oral carbenoxolone improves hepatic insulin sensitivity [16] and has a greater effect in nonobese glucose-intolerant patients than healthy control subjects [17]. The expression of $11 \beta-H S D 1$ in myoblast cultures stimulated with glucocorticoids was negatively correlated with insulin sensitivity [18]. The 11ß-HSD1 knockout mice develop resistance to diet-induced hyperglycaemia through attenuation of hepatic gluconeogenic enzymes [19] and increased hepatic insulin sensitivity [20]. Notably, inhibition of $11 \beta-H S D 1$ activity in the pancreas causes beta cells to secrete more insulin [21].

Here we expanded the expression study in isolated abdominal subcutaneous adipocytes of a larger group of Pima Indians, since an in situ hybridisation study showed that obese individuals had increased 11ß-HSD1 mRNA expression in the adipocyte compartment of subcutaneous adipose tissue [8]. To better understand the role of $11 \beta$-HSD1 in the development of obesity and insulin resistance, we also measured the $11 \beta$-HSD1 mRNA concentrations in skeletal muscle tissues of a separate group of Pima Indians who had undergone detailed metabolic characterisation. Furthermore, we analysed the HSD11B1 gene to identify single nucleotide polymorphisms that might associate with the metabolic phenotypes.

\section{Materials and methods}

Subjects. All subjects provided written informed consent prior to participation. All studies were approved by the Tribal Council of the Gila River Indian Community and the Institutional Review Board of the National Institutes of Diabetes and Digestive and Kidney Diseases (NIDDK). Subcutaneous abdominal fat biopsies were obtained from 61 non-diabetic Pima or Tohono O'Odham Indians. Eight of these subjects overlapped with our previous study [9]. Muscle biopsies were obtained from 64 nondiabetic Pima or Tohono O'Odham subjects, 17 of whom also underwent the adipose tissue biopsy. All subjects with muscle biopsies and a subset of subjects with fat biopsies $(n=30)$ underwent euglycaemic-hyperinsulinaemic clamp as described below. The anthropometric and metabolic variables of the subjects are described in Table 1. All subjects undergoing biopsies were in good health as determined by their medical history, physical examination and routine blood and urine tests, and none were taking medication at the time of the study. Genotyping and association studies were done in $~ 800$ full-blooded Pima Indians who participated in our ongoing longitudinal study of the aetiology of Type 2 diabetes mellitus among the Gila River Indian Community in Arizona [22], which included a subset of $\sim 150$ subjects who underwent euglycaemic-hyperinsulinaemic clamp. Genotype data were available in all 61 subjects of the adipocyte expression study, and in 40 out of the 64 subjects of the muscle expression study. Diabetic status was determined according to the criteria of the World Health Organisation [23].

Table 1. Clinical characteristics of subjects for the adipose and muscle tissue biopsies

\begin{tabular}{|c|c|c|c|}
\hline Sex (male/female) & $37 / 24$ & $18 / 12$ & $37 / 27$ \\
\hline Age (years) & $30 \pm 7$ & $31 \pm 7$ & $30 \pm 7$ \\
\hline Weight (kg) & $104 \pm 37$ & $92 \pm 25$ & $99 \pm 28$ \\
\hline Body fat $(\%)$ & $33 \pm 8$ & $32 \pm 7$ & $33 \pm 7$ \\
\hline Waist (cm) & $113 \pm 23$ & $105 \pm 18$ & $108 \pm 20$ \\
\hline Fasting plasma glucose (mmol/l) & $5.0 \pm 0.5$ & $4.9 \pm 0.5$ & $4.9 \pm 0.5$ \\
\hline Plasma glucose at $2 \mathrm{~h}(\mathrm{mmol} / \mathrm{l})$ & $6.6 \pm 1.8$ & $6.8 \pm 1.8$ & $6.8 \pm 1.8$ \\
\hline Fasting plasma insulin $(\mu \mathrm{U} / \mathrm{ml})$ & $44 \pm 17$ & $42 \pm 15$ & $42 \pm 17$ \\
\hline
\end{tabular}

EMBS, estimated metabolic body size; ${ }^{\mathrm{a}} n=59 ; \mathrm{b} n=63$ 
Metabolic measurements. Volunteers were admitted to the Clinical Research Unit where they consumed a weight-maintaining diet (containing $50 \%$ of calories as carbohydrates, $30 \%$ as fat and $20 \%$ as protein) for 2 to 3 days before clinical testing. Body composition was measured by dual energy X-ray absorptiometry (DXA) using a total body scanner (DPX-L, Lunar Radiation, Madison, Wis., USA) as described previously [24]. Waist circumference was measured at the umbilicus in the supine position. All subjects with muscle biopsies and a subset of subjects with fat biopsies $(n=30)$ underwent euglycaemic-hyperinsulinaemic clamp as described previously [25]. Briefly, after an overnight fast, a primed continuous intravenous insulin infusion was administered for $100 \mathrm{~min}$ at a constant rate of $40 \mathrm{mU} \cdot \mathrm{m}^{-2}$ body surface area $\mathrm{min}^{-1}$ (low-dose insulin; M-low), followed by a second insulin infusion for $100 \mathrm{~min}$ at $400 \mathrm{mU} \cdot \mathrm{m}^{-2} \mathrm{~min}^{-1}$ (high-dose insulin; M-high). Steady-state plasma insulin concentrations of $155 \pm 26 \mu \mathrm{U} / \mathrm{ml}$ and $2481 \pm 320 \mu \mathrm{U} / \mathrm{ml}$ respectively were achieved. Plasma glucose concentrations were maintained at $\sim 5.5 \mathrm{mmol} / \mathrm{l}$ with a variable infusion of a $20 \%$ glucose solution. Rates of insulin-stimulated glucose disposal at lowdose and high-dose insulin concentrations were calculated for the last $40 \mathrm{~min}$ of each insulin infusion. The rate of endogenous glucose production was measured before insulin infusion (BSGO) and during the last $40 \mathrm{~min}$ of the low-dose insulin infusion (ENDM), using tritiated glucose and calculated from the Steele equation [26]. All measurements derived from the glucose clamp were normalised to estimated metabolic body size (EMBS, which equals fat-free mass $+17.7 \mathrm{~kg}$ ).

Fat biopsy and isolation of adipocyte RNA. After an overnight fast, subjects underwent subcutaneous abdominal fat needle biopsies under local anaesthesia with $1 \%$ lidocaine. The adipose biopsy was placed on a sterile nylon mesh and rinsed with sterile $0.9 \% \mathrm{NaCl}$ solution. The tissue was then cleaned of visible connective tissue and blood vessels in Hank's Buffered Saline Solution (HBBS) supplemented with $5.5 \mathrm{mmol} / \mathrm{l}$ glucose. For adipocyte isolation, adipose tissue was digested in HBBS buffer containing $5.5 \mathrm{mmol} / \mathrm{l}$ glucose, 5\% fatty acid free BSA (Introgen/Serologicals, Norcross, Ga., USA) and $3.3 \mathrm{mg} / \mathrm{ml}$ type I collagenase (Worthington Biochemical, Lakewood, N.J., USA) for $30 \mathrm{~min}$ in a water bath at $37{ }^{\circ} \mathrm{C}$. The digestion mixture was passed through a sterile $230 \mathrm{~mm}$ stainless steel tissue sieve (Thermo EC, Holbrook, N.Y., USA) and the adipocytes were allowed to float by buoyancy. The supernatant containing adipocytes was collected. Adipocyte RNA was extracted using RNeasy Mini Kit from Qiagen (Valencia, Calif., USA). During the extraction, RNA was treated with DNAse using RNAse-free DNAse Set (Qiagen) per manufacturer's instruction.

Muscle biopsy and RNA extraction. Percutaneous needle biopsies were done on the vastus lateralis muscle under local anaesthesia with $1 \%$ lidocaine after a 12-h overnight fast and the biopsy specimens were immediately frozen in liquid nitrogen as described previously [27]. Total RNA was isolated from the frozen tissues homogenised in TRIzol Reagent (Life Technologies, Gaithersburg, Mass., USA) and further purified using RNeasy Mini Kit and RNAse-free DNAse Set (Qiagen) as described above.

cDNA synthesis. The quality of the RNA was assessed by agarose gel electrophoresis. One microgram of RNA from each sample was used to prepare oligo dT-primed cDNA using the Advantage RT for PCR kit (Clontech, Palo Alto, Calif., USA) following the manufacturer's recommendation and the cDNA was stored at $-70{ }^{\circ} \mathrm{C}$. Successful cDNA synthesis was verified by PCR amplification of $\beta 2$-microglobulin transcript using for- ward primer 5'-TGTCTTTCAGCAAGGACTGGTC-3' and reverse primer 5'-TGATGCTGCTTACATGTCTCGAT-3'.

Quantitative real-time PCR. The $11 \beta$-HSD1 transcript was quantified with Real Time PCR primer-probe sets using the ABI PRISM 7700 Sequence Detection System (Applied Biosystems, Foster City, Calif., USA). The sequences for the $11 \beta$-HSD1 primers and Taqman probe were designed using Primer Express 1.5 software (Applied Biosystems). Primers were synthesised by Integrated DNA Technologies, (Coralville, Ia., USA). The probe sequence was 5'-6FAM CTTGGCCTCATAGACACAGAAACAGCCA BHQ1-3' (Biosearch Technologies, Novato, Calif., USA). The sequence of the $11 \beta$ HSD1 forward primer was 5'-GGAATATTCAGTGTCCAGGGTCAA-3' and the reverse primer was 5'-TGATCTCCAGGGCACATTCCT-3'. The human TATA box binding protein (TBP) gene transcript with optimised primers and probe (Pre-developed Taqman Assay Reagents Endogenous Control Human TBP kit, Applied Biosystems) was used as the normalisation gene. Real-time PCR was done by using Universal Taqman mix in the ABI 7700 sequence detector (Applied Biosystems). The final concentrations of primers and probe were $0.9 \mathrm{mmol} / \mathrm{l}$ and $0.25 \mathrm{mmol} / \mathrm{l}$ respectively. A standard curve for each primer-probe set was generated by serial dilution of a randomly chosen cDNA sample done in triplicate. Each sample was run in duplicate and the mean values of the duplicates were used to calculate transcript level. Real-time PCR was carried out as recommended by the manufacturer as follows: $50{ }^{\circ} \mathrm{C}, 2 \mathrm{~min} ; 95^{\circ} \mathrm{C}, 10 \mathrm{~min} ; 95^{\circ} \mathrm{C}, 15 \mathrm{~s}$ and $60{ }^{\circ} \mathrm{C}$, 1 min for 40 cycles.

Identification and genotyping of polymorphisms. Genomic DNA samples from 20 non-diabetic unrelated Pima Indian subjects were sequenced across a $\sim 4.0 \mathrm{~kb}$ region upstream of the transcription initiation site, the six exons, exon-intron junctions and the $5^{\prime}$ and $3^{\prime}$ UTR of HSD11B1 gene. Samples were amplified in a GeneAmp PCR system 9700 as follows: $94{ }^{\circ} \mathrm{C}$, $4 \mathrm{~min} ; 94^{\circ} \mathrm{C}, 15 \mathrm{~s} ; 60{ }^{\circ} \mathrm{C}, 45 \mathrm{~s}$ and $72{ }^{\circ} \mathrm{C}, 1 \mathrm{~min}$ for 35 cycles; $72{ }^{\circ} \mathrm{C}, 5 \mathrm{~min}$. Big Dye Terminator (Applied Biosystems) was used to do cycle sequencing and the samples were analysed on an automated capillary sequencer (model 3700, Applied Biosystems). Genotyping was done by the allelic discrimination TaqMan Assay by design (Applied Biosystems) for SNP5 and by direct sequencing using Big Dye Terminator, as described above, for SNP1 in full-blooded Pima Indian subjects. The allelic discrimination assay PCR was done as follows: $50{ }^{\circ} \mathrm{C}, 2 \mathrm{~min} ; 95^{\circ} \mathrm{C}, 10 \mathrm{~min} ; 92^{\circ} \mathrm{C}, 15 \mathrm{~s}$ and $60{ }^{\circ} \mathrm{C}, 1 \mathrm{~min}$ for 40 cycles in the 7700 Sequence detector (Applied Biosystems).

Statistical analysis. Statistical analyses were done by using the procedures of the Statistical Analysis System software (SAS Institute, Cary, N.C., USA). 11 $\beta$-HSD1 mRNA levels were normalised to TBP by taking the residual values of $11 \beta$-HSD1 after linear regression to TBP transcript level. For the metabolic association analyses, plasma insulin concentrations and rates of glucose disappearance during the low-dose insulin infusion were logarithmically transformed to approximate normal distributions. General linear regression models were used to assess the relationships between mRNA concentrations or genotypes and measures of obesity and insulin action. For continuous variables, the generalised estimating equation (GEE) procedure was used to adjust for the appropriate covariates. The association analyses between adipocyte mRNA levels and metabolic variables were not adjusted for nuclear family membership since there were only five first-degree relatives in this dataset. However, the genotyped dataset had first, second or more degree relatives and all the association analyses between 
genotypes and metabolic measures were adjusted for nuclear family membership. The Student's $t$ test was done to evaluate genotype associations with expression levels.

The association analyses of genotypes with diabetes or obesity were done in full-blooded Pima Indians. The odds ratio was used to determine the strength of the association between the prevalence of the at-risk genotype and affection status. Associations were calculated under three different models: dominant, recessive, and additive. Linkage disequilibrium (LD) between SNPs was calculated with the Estimating Haplotypes program. The degree of LD was quantified by $\mathrm{D}^{\prime}$, which represents the extent of LD between alleles, expressed as a proportion of the maximum possible. The amount of shared information was expressed in $r^{2}$.

A $p$ value of less than 0.05 was considered significant.

\section{Results}

The adipocyte $11 \beta$-HSD1 mRNA concentrations correlated positively with measures of obesity (\% body fat and waist circumference) as well as fasting and 2-h plasma insulin concentrations during the OGTT (Table 2). In a subset of subjects who agreed to undergo a euglycaemic-hyperinsulinaemic clamp $(n=30$; Table 1), the adipocyte $11 \beta$-HSD1 mRNA concentrations also correlated negatively with glucose disposal rates at physiological and maximally stimulating insulin concentrations (Table 2). These correlations remained significant after adjusting for age and sex (Table 2).

Sequencing of the $H S D 11 B 1$ gene $(\sim 4.0 \mathrm{~kb}$ region upstream of the transcription initiation site, the six exons, exon-intron junctions and the $5^{\prime}$ and $3^{\prime}$ UTR) in DNA from 20 Pima Indians identified six variants (Table 3). Genotyping of these SNPs was carried out in 100 subjects to assess the extent of linkage disequilibrium. SNPs 1 and 2 were in 100\% linkage disequilibrium with each other, and SNP4, SNP5 and SNP6 were in $100 \%$ linkage disequilibrium among themselves. SNP3 was very rare with a minor allele frequency of $1.7 \%$, which we did not genotype further. Therefore SNP1 and SNP5 were selected as representatives of the two common genotypic groups, and were further genotyped for association studies in $\sim 800$ full-blooded Pima Indians. Analysis of this larger number of genotypes showed that, despite differences in frequencies, the common alleles at $\operatorname{SNP} 1(G, 0.86)$ and SNP5 $(G, 0.54)$ were in very high linkage disequi- librium $\left(\mathrm{D}^{\prime}=0.98\right)$. The amount of shared information was relatively low $\left(r^{2}=0.21\right)$.

In the genotyped full-blooded Pima Indians, both SNP1 $(n=706)$ and SNP5 $(n=839)$ were associated with Type 2 diabetes mellitus under both additive ( $p=0.01$ and 0.02 respectively) and recessive ( $p=0.01$ for both SNPs) analytical models (Table 4). Among the subjects with normal glucose tolerance who had additionally undergone a euglycaemic-hyperinsulinaemic clamp, SNP1 $(n=127)$ and SNP5 $(n=159)$ were also associated with glucose uptake rates at maximally stimulating insulin concentrations ( $p=0.03$ and $p=0.04$ respectively, after adjusting for age, sex, \% fat and nuclear family membership; Table 5). SNP1 was additionally associated with fasting, $30 \mathrm{~min}$ and 2-h plasma insulin concentrations in response to a $75-\mathrm{g}$ OGTT, $(p=0.002, p=0.002$ and $p=0.03$ respectively, after adjusting for age, sex, $\%$ fat and nuclear family membership). This SNP remained significantly associated with fasting insulin $(p=0.02)$ and early insulin secretion (plasma insulin at 30-min; $p=0.003$ ) after adjusting for age, sex, \% fat, 30-min glucose and glucose disposal rate at high-dose insulin concentrations and nuclear family membership. No significant associations were found between SNP1 or SNP5 and age, $\%$ fat, fasting, 30-min and 2-h glucose concentrations, glucose disposal rate at physiological insulin concentrations, and measures of hepatic insulin sensitivity (data not shown).

Although SNP5 was not significantly associated with plasma insulin concentrations in response to an OGTT, it showed the same trend as observed with SNP1 (Fig. 1). For example, subjects homozygous for the rare allele (TT) at SNP5 had increased mean plasma insulin concentrations at $30 \mathrm{~min}$, despite having similar glucose concentrations. These subjects, homozygous for the $T$ allele at SNP5, also had a significant decrease in glucose disposal, compared with subjects homozygous for the common allele $(G G)$.

Both SNP1 $(p=0.3, n=613)$ and SNP5 $(p=0.8$, $n=728$ ) were not associated with BMI. In addition, these SNPs were not associated with 11ß-HSD1 mRNA concentrations in the abdominal subcutaneous adipocyte biopsies of 61 Pima Indians; for SNP1 (GG vs $G A$; No $A A$ s available) $p=0.32$, and for SNP5 $(G G+G T$ vs $T T) p=0.89$.

Table 2. Pearson correlations of the normalised $H S D 11 B 1$ expression in adipocytes with in vivo metabolic variables

\begin{tabular}{lcrrrr}
\hline Metabolic variables & $r$ & $p$ value & $r^{\mathrm{a}}$ & $p$ value & $n$ \\
\hline \% Body fat & 0.39 & 0.002 & 0.60 & $<0.0001$ & 61 \\
Waist circumference & 0.77 & $<0.0001$ & 0.75 & $<0.0001$ & 61 \\
Fasting plasma insulin & 0.68 & $<0.0001$ & 0.66 & $<0.0001$ & 61 \\
2-h plasma insulin & 0.53 & $<0.0001$ & 0.55 & $<0.0001$ & 59 \\
Glucose disposal rate at physiological insulin clamp & -0.60 & 0.0004 & -0.62 & 0.0003 & 30 \\
Glucose disposal rate maximally stimulating insulin clamp & -0.42 & 0.02 & -0.36 & 0.047 & 30 \\
\hline
\end{tabular}

a Adjusted for age and sex 
$\mathbf{a}$

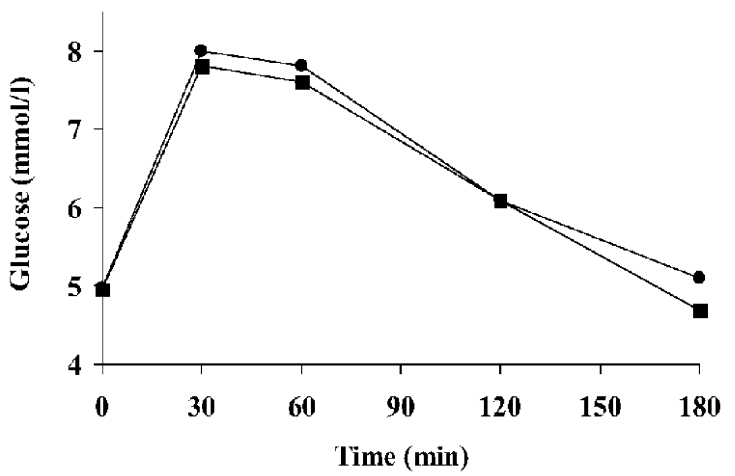

b

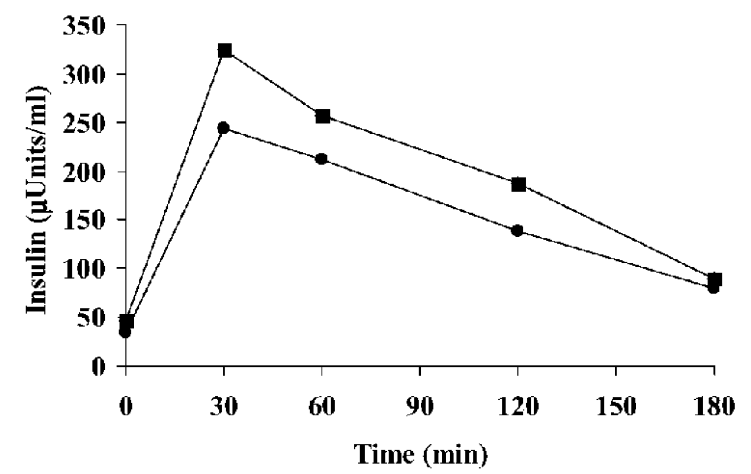

c

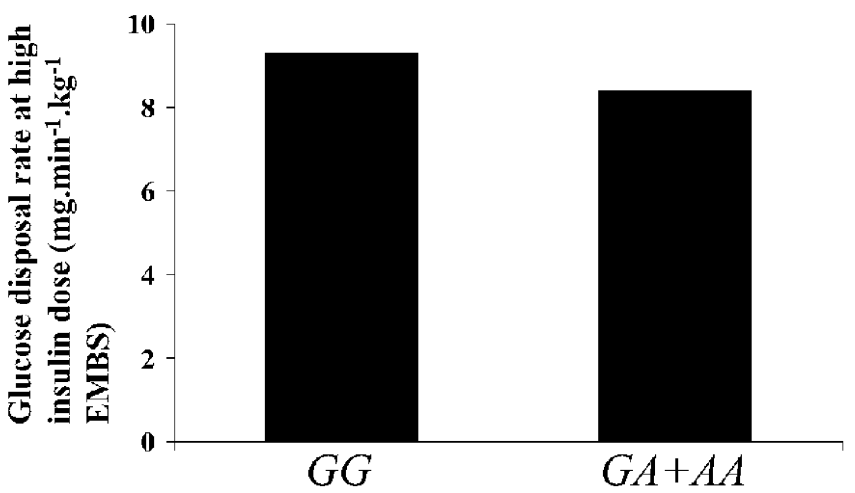

Fig. 1. Metabolic responses in subjects based on their genotype for SNP1. Glucose (a) and insulin (b) curves are in response to a $75 \mathrm{~g}$ OGTT. The glucose disposal rates (c) were measured during maximally stimulating insulin infusion $(2481 \pm 320 \mu \mathrm{U} / \mathrm{ml})$. Given the low frequency of homozygotes for the rare allele for SNP1 (AA genotype), for statistical purposes these subjects were combined with the heterozygous subjects $(G A)$ and this group was compared to the homozygotes for the common allele $(G G)$. $G G$, circles; $A A+G A$, squares

Since SNP1 and SNP5 were associated with glucose disposal rate, which is primarily due to glucose uptake in the muscle, we investigated whether this association was attributable to differential $11 \beta$-HSD1 expression levels in skeletal muscle. There was no association between skeletal muscle $11 \beta$-HSD1 mRNA concentration and fasting plasma insulin $(\mathrm{r}=-0.05$; $p=0.68)$ or plasma insulin at $2 \mathrm{~h}(\mathrm{r}=0.04 ; p=0.77)$ dur- 
Table 4. Genotypic distribution for SNP1 and SNP5 based on diabetic status

\begin{tabular}{|c|c|c|c|c|c|c|c|c|}
\hline & \multirow[t]{3}{*}{ Status } & \multicolumn{3}{|l|}{ Genotype } & \multirow{2}{*}{\multicolumn{2}{|c|}{$\begin{array}{l}A \text { allele Dominant Model } \\
(A A+G A \text { vs } G G)\end{array}$}} & \multirow{2}{*}{\multicolumn{2}{|c|}{$\begin{array}{l}\text { Additive Model } \\
\text { (per number of } A \text { alleles) }\end{array}$}} \\
\hline & & \multirow{2}{*}{$G G$} & \multirow{2}{*}{$G A$} & \multirow{2}{*}{$A A$} & & & & \\
\hline & & & & & OR $(95 \% \mathrm{CI})$ & $p$ value & OR $(95 \% \mathrm{CI})$ & $p$ value \\
\hline \multirow[t]{5}{*}{ SNP1 } & Non-diabetic & $226(81.6)$ & $48(17.3)$ & $3(1.1)$ & \multirow[t]{2}{*}{$1.72(1.14-2.56)$} & \multirow[t]{2}{*}{0.01} & \multirow{2}{*}{$1.64(1.11-2.38)$} & \multirow[t]{2}{*}{0.01} \\
\hline & Diabetic & $310(72.3)$ & $109(25.4)$ & $10(2.3)$ & & & & \\
\hline & \multirow[t]{3}{*}{ Status } & \multicolumn{3}{|l|}{ Genotype } & \multirow{2}{*}{\multicolumn{2}{|c|}{$\begin{array}{l}T \text { allele Recessive Model } \\
(T T \text { vs } G G+G T)\end{array}$}} & \multirow{2}{*}{\multicolumn{2}{|c|}{$\begin{array}{l}\text { Additive Model } \\
\text { (per number of } T \text { alleles) }\end{array}$}} \\
\hline & & \multirow{2}{*}{$G G$} & \multirow{2}{*}{$G T$} & \multirow{2}{*}{$T T$} & & & & \\
\hline & & & & & OR $(95 \% \mathrm{CI})$ & $p$ value & OR $(95 \% \mathrm{CI})$ & $p$ value \\
\hline \multirow[t]{2}{*}{ SNP5 } & Non-diabetic & $121(36.8)$ & $166(50.5)$ & $42(12.8)$ & \multirow{2}{*}{$1.79(1.14-2.8)$} & \multirow[t]{2}{*}{0.01} & \multirow[t]{2}{*}{$1.34(1.05-1.72)$} & \multirow[t]{2}{*}{0.02} \\
\hline & Diabetic & $158(31)$ & $238(46.7)$ & $114(22.4)$ & & & & \\
\hline
\end{tabular}

Number of subjects with each genotype and their percent of total in parentheses are given. Odds ratios (with 95\% CI in parentheses) and significant $p$ values from analyses under dominant, recessive, and additive models are presented. Data were adjusted for age, sex, birth date, and nuclear family membership

Table 5. Association of SNP1 and SNP5 with insulin sensitivity in Pima Indians with normal glucose tolerance

\begin{tabular}{|c|c|c|c|c|c|c|c|}
\hline & \multicolumn{4}{|l|}{$\mathrm{SNP}^{\mathrm{a}}$} & \multicolumn{3}{|l|}{$\mathrm{SNP}^{\mathrm{b}}$} \\
\hline & $\begin{array}{l}G G \\
(100)\end{array}$ & $\begin{array}{l}G A+A A \\
(27)\end{array}$ & $p$ value ${ }^{c}$ & $p$ value $^{\mathrm{d}}$ & $\begin{array}{l}G T+G G \\
(135)\end{array}$ & $\begin{array}{l}T T \\
(24)\end{array}$ & $\begin{array}{l}p \text { value }^{c} \\
\text { Recessive }\end{array}$ \\
\hline Fasting plasma insulin $(\mu \mathrm{U} / \mathrm{ml})$ & $35 \pm 2$ & $46 \pm 5$ & 0.002 & 0.02 & $37 \pm 2$ & $47 \pm 5$ & 0.22 \\
\hline Plasma insulin at $30 \mathrm{~min}(\mu \mathrm{U} / \mathrm{ml})$ & $244 \pm 16$ & $324 \pm 31$ & 0.002 & 0.003 & $252 \pm 14$ & $320 \pm 44$ & 0.26 \\
\hline Plasma insulin at $2 \mathrm{~h}(\mu \mathrm{U} / \mathrm{ml})$ & $139 \pm 10$ & $187 \pm 24$ & 0.03 & 0.06 & $148 \pm 10$ & $182 \pm 26$ & 0.91 \\
\hline $\begin{array}{l}\text { Glucose disposal rate at maximally } \\
\text { stimulating insulin during clamp } \\
\left(\mathrm{mg} \cdot \mathrm{kg}^{-1} \mathrm{EMBS} \cdot \mathrm{min}^{-1}\right)\end{array}$ & $9.3 \pm 0.2$ & $8.4 \pm 0.4$ & $\mathbf{0 . 0 3}$ & & $9.4 \pm 0.2$ & $8.3 \pm 0.4$ & 0.04 \\
\hline
\end{tabular}

a Due to the low frequency of SNP1, for statistical analyses, the homozygotes for the rare allele $(A A)$ were combined with the heterozygotes $(G A)$, and this combined genotypic group was then compared to the more common homozygous $(G G)$. ${ }^{\mathrm{b}}$ For SNP5, data is analysed under a recessive model where the common $(G G)$ subjects are combined with the heterozygotes

ing OGTT and glucose disposal rates at physiological insulin concentration $(\mathrm{r}=-0.06 ; p=0.65)$ or high insulin dose $(\mathrm{r}=0.04 ; p=0.78)$ during euglycaemic-hyperinsulinaemic clamp in a separate group of 64 Pima Indians (as described in Materials and methods). In addition, SNP1 ( $G G$ vs $G A$; No $A A \mathrm{~s}, p=0.8$ ) and SNP5 $(G G+G T$ vs $T T p=0.08)$ did not show any associations with the muscle $11 \beta$-HSD1 expression levels.

\section{Discussion}

In this study, we identified single nucleotide polymorphisms (SNPs) in the $5^{\prime}$ upstream and intronic regions of the HSD $11 B 1$ gene in Pima Indians that were associated with Type 2 diabetes mellitus and insulin resis-
$(G T) .{ }^{\mathrm{c}}$ Adjusted for age, sex, percent body fat and nuclear family membership; d adjusted for age, sex, percent body fat, glucose, glucose disposal rate at high-dose insulin and nuclear family membership (when $p$ values $^{c}$ were significant). The $p$ values $<0.05$ are shown in bold

tance, but not with obesity. The lack of association with BMI was also observed in a study that genotyped two microsatellite markers within the HSDI1B1 locus in two other populations [28]. SNP4 and 5 polymorphisms were identified in 8 individuals, but no correlation with obesity was found [29]. We also showed that increased 11 $\beta$-HSD1 mRNA concentrations in isolated abdominal subcutaneous adipocytes correlated with increased obesity and plasma insulin concentrations as well as decreased insulin action as determined by glucose disposal rates. In contrast, there was no direct correlation between skeletal muscle 11 -HSD1 mRNA concentrations and insulin action. The results indicate that $11 \beta-H S D 1$ is likely to have a complex role in determining adiposity and insulin action, which may be due to tissue-specific regulation of this enzyme. 
SNP1, which is in 100\% linkage disequilibrium with SNP2, was associated with Type 2 diabetes mellitus, fasting, 30-min and 2-h plasma insulin concentrations in response to an OGTT, and glucose disposal rate in response to a high-dose insulin clamp. Since both SNP1 and SNP2 are located in the $5^{\prime}$ upstream region of the HSD11B1 gene, if either SNP is a functional variant, it would alter the mRNA concentration of the gene. A report has shown that two other $5^{\prime}$ upstream region SNPs of the HSD11B1 gene (not present in the individuals we sequenced) are associated with reduced transcription [30]. Functional studies to investigate the potential effects of SNPs 1 and 2 on promoter activity are warranted. SNP5, which is in 100\% linkage disequilibrium with SNP4 and SNP6, was similarly associated with Type 2 diabetes mellitus and glucose disposal in response to a high-dose insulin clamp. SNP4 and SNP5 are both intronic, and SNP6 is in the 3'UTR. Both SNPs 4 and 5 act as intronic enhancers that modulate $11 \beta$-HSD1 expression and activity [31]. Nevertheless, given the lack of association between SNP1 or SNP5 and obesity, there was no association between these SNPs and adipocyte $11 \beta$ HSD1 mRNA concentrations in the 61 subjects that we studied.

Although not tested in this study, the genetic variants in $H S D 11 B 1$ gene may affect $11 \beta$-HSD1 expression in tissues other than adipose or muscle. Since there is a notable association between SNP1 in the $H S D 11 B 15^{\prime}$ upstream region with early (30 min) insulin secretion, it is possible that either this SNP1 or SNP2, which is in $100 \%$ LD with SNP1 and also in the $5^{\prime}$ upstream region of the gene, modulates $11 \beta$ HSD1 expression in pancreatic beta cells. It has recently been reported that the 11 $\beta$-HSD1 expression and activity were increased in islets of diabetic Zucker Diabetic Fatty rats [32]. This enzyme is also expressed in human pancreatic islets [21], and carbenoxolone, an inhibitor of $11 \beta$-HSD1 activity, can reverse inhibition of insulin secretion in pancreatic beta cells from ob/ob mice by glucocorticoids [21]. Another possibility of genetic variants in the HSD11B1 gene affecting the enzyme expression in the liver seems unlikely, because we did not observe any associations between the SNPs in HSD11B1 gene and measures of hepatic insulin sensitivity.

Screening the $5^{\prime}$ upstream sequences with MatInspector showed a heat shock factor transcription binding site in the SNP1 region. SNP2 is located in a stretch of nucleotides (TATTA(T/C)TTT TTA) that shares homology with the consensus MEF2 (myocyte enhancer factor 2) binding sequence $\mathrm{CTA}(\mathrm{A} / \mathrm{T})_{4}$ $\mathrm{TA}(\mathrm{G} / \mathrm{A})$ [33] and also the consensus insulin promoter factor 1 (IPF1) sequence C/TTAATG on the complementary strand [34]. MEF2 isoforms are expressed in muscle and non-muscle cells in a cell-type-specific manner [35, 36]. The levels of MEF2 factors and DNA binding activity are decreased in skeletal muscle
[36] and adipose tissue of STZ-induced insulin-deficient diabetic mice [37]. The IPF1 (PDX1/Pancreatic duodenal homeobox 1) is primarily expressed in beta cells and is required for pancreatic development and maintenance of beta cell function [38]. It is a key transcription regulator of many genes including insulin [39] and amylin [34]. Direct functional studies of these putative consensus binding sites in the $5^{\prime}$ upstream region of the $H S D 11 B 1$ gene are required to elucidate their role, if any, in regulating tissue-specific $H S D 11 B 1$ transcription.

Our results suggest that $11 \beta$-HSD1 is likely to have a complex role in determining adiposity and insulin action, which may be due to tissue-specific regulation of this enzyme. We propose that $11 \beta$-HSD1 activity in humans contributes to alterations in early insulin secretion, insulin resistance, and ultimately to increased risk of Type 2 diabetes mellitus through both an adiposity-associated mechanism (i.e. increased adipose mass results in increased adipose-specific 11 $\beta$-HSD1 expression and pleotropic secondary effects cause insulin resistance) and an adiposity-independent mechanism. However, future studies in the Pima Indians, as well as replication of our findings in other metabolically characterised populations are necessary to substantiate these hypotheses.

Acknowledgements. We would like to thank the Pima Indian community for their participation, the clinical staff for their patient care, Emma Rousseau for excellent technical assistance as well as Dr Rob Hanson and Sayuko Kobes for the linkage disequilibrium and association analyses (with diabetes and BMI).

\section{References}

1. Bujalska IJ, Kumar S, Hewison M, Stewart PM (1999) Differentiation of adipose stromal cells: the roles of glucocorticoids and 11beta-hydroxysteroid dehydrogenase. Endocrinology 140:3188-3196

2. Napolitano A, Voice MW, Edwards CR, Seckl JR, Chapman KE (1998) 11Beta-hydroxysteroid dehydrogenase 1 in adipocytes: expression is differentiation-dependent and hormonally regulated. J Steroid Biochem Mol Biol 64: 251-260

3. Ricketts ML, Verhaeg JM, Bujalska I, Howie AJ, Rainey WE, Stewart PM (1998) Immunohistochemical localization of type 1 11beta-hydroxysteroid dehydrogenase in human tissues. J Clin Endocrinol Metab 83:1325-1335

4. Whorwood CB, Donovan SJ, Wood PJ, Phillips DI (2001) Regulation of glucocorticoid receptor alpha and beta isoforms and type I 11beta-hydroxysteroid dehydrogenase expression in human skeletal muscle cells: a key role in the pathogenesis of insulin resistance? J Clin Endocrinol Metab 86:2296-2308

5. Seckl JR, Walker BR (2001) Minireview: 11beta-hydroxysteroid dehydrogenase type $1-$ a tissue-specific amplifier of glucocorticoid action. Endocrinology 142:1371-1376

6. Rask E, Olsson T, Soderberg S et al. (2001) Tissue-specific dysregulation of cortisol metabolism in human obesity. J Clin Endocrinol Metab 86:1418-1421

7. Rask E, Walker BR, Soderberg S et al. (2002) Tissuespecific changes in peripheral cortisol metabolism in obese 
women: increased adipose 11beta-hydroxysteroid dehydrogenase type 1 activity. J Clin Endocrinol Metab 87: 3330-3336

8. Paulmyer-Lacroix O, Boullu S, Oliver C, Alessi MC, Grino M (2002) Expression of the mRNA coding for 11betahydroxysteroid dehydrogenase type 1 in adipose tissue from obese patients: an in situ hybridization study. J Clin Endocrinol Metab 87:2701-2705

9. Lindsay RS, Wake DJ, Nair S et al. (2003) Subcutaneous adipose 11 beta-hydroxysteroid dehydrogenase type 1 activity and messenger ribonucleic acid levels are associated with adiposity and insulinemia in Pima Indians and Caucasians. J Clin Endocrinol Metab 88:2738-2744

10. Wake DJ, Rask E, Livingstone DE, Soderberg S, Olsson T, Walker BR (2003) Local and systemic impact of transcriptional up-regulation of 11beta-hydroxysteroid dehydrogenase type 1 in adipose tissue in human obesity. J Clin Endocrinol Metab 88:3983-3988

11. Westerbacka J, Yki-Jarvinen H, Vehkavaara S et al. (2003) Body fat distribution and cortisol metabolism in healthy men: enhanced 5beta-reductase and lower cortisol/cortisone metabolite ratios in men with fatty liver. J Clin Endocrinol Metab 88:4924-4931

12. Tomlinson JW, Sinha B, Bujalska I, Hewison M, Stewart PM (2002) Expression of 11beta-hydroxysteroid dehydrogenase type 1 in adipose tissue is not increased in human obesity. J Clin Endocrinol.Metab 87:5630-5635

13. Masuzaki H, Paterson J, Shinyama H et al. (2001) A transgenic model of visceral obesity and the metabolic syndrome. Science 294:2166-2170

14. Andrews RC, Herlihy O, Livingstone DE, Andrew R, Walker BR (2002) Abnormal cortisol metabolism and tissue sensitivity to cortisol in patients with glucose intolerance. J Clin Endocrinol Metab 87:5587-5593

15. Stewart PM, Boulton A, Kumar S, Clark PM, Shackleton CH (1999) Cortisol metabolism in human obesity: impaired cortisone $\rightarrow$ cortisol conversion in subjects with central adiposity. J Clin Endocrinol Metab 84:10221027

16. Walker BR, Connacher AA, Lindsay RM, Webb DJ, Edwards CR (1995) Carbenoxolone increases hepatic insulin sensitivity in man: a novel role for 11-oxosteroid reductase in enhancing glucocorticoid receptor activation. J Clin Endocrinol Metab 80:3155-3159

17. Andrews RC, Rooyackers O, Walker BR (2003) Effects of the 11 beta-hydroxysteroid dehydrogenase inhibitor carbenoxolone on insulin sensitivity in men with type 2 diabetes. J Clin Endocrinol Metab 88:285-291

18. Whorwood CB, Donovan SJ, Flanagan D, Phillips DI, Byrne CD (2002) Increased glucocorticoid receptor expression in human skeletal muscle cells may contribute to the pathogenesis of the metabolic syndrome. Diabetes 51:10661075

19. Kotelevtsev Y, Holmes MC, Burchell A et al. (1997) 11beta-hydroxysteroid dehydrogenase type 1 knockout mice show attenuated glucocorticoid-inducible responses and resist hyperglycemia on obesity or stress. Proc Natl Acad Sci USA 94:14924-14929

20. Morton NM, Holmes MC, Fievet C et al. (2001) Improved lipid and lipoprotein profile, hepatic insulin sensitivity, and glucose tolerance in 11beta-hydroxysteroid dehydrogenase type 1 null mice. J Biol Chem 276:41293-41300

21. Davani B, Khan A, Hult M et al. (2000) Type 111 betahydroxysteroid dehydrogenase mediates glucocorticoid activation and insulin release in pancreatic islets. $\mathrm{J}$ Biol Chem 275:34841-34844
22. Hanson RL, Ehm MG, Pettitt DJ et al. (1998) An autosomal genomic scan for loci linked to type II diabetes mellitus and body-mass index in Pima Indians. Am J Hum Genet 63:1130-1138

23. World Health Organization (1980) WHO Expert Committee on Diabetes Mellitus: Second report. World Health Organization, Geneva, Technical Report Series No. 646

24. Tataranni PA, Ravussin E (1995) Use of dual-energy X-ray absorptiometry in obese individuals. Am J Clin Nutr 62:730-734

25. Lillioja S, Mott DM, Zawadzki JK et al. (1987) In vivo insulin action is familial characteristic in nondiabetic Pima Indians. Diabetes 36:1329-1335

26. Steele R (1959) Influences of glucose loading and of injected insulin on hepatic glucose output. Ann NY Acad Sci 82:420-430

27. Majer M, Mott DM, Mochizuki H et al. (1996) Association of the glycogen synthase locus on 19q13 with NIDDM in Pima Indians. Diabetologia 39:314-321

28. Draper N, Echwald SM, Lavery GG et al. (2002) Association studies between microsatellite markers within the gene encoding human 11beta-hydroxysteroid dehydrogenase type 1 and body mass index, waist to hip ratio, and glucocorticoid metabolism. J Clin Endocrinol Metab 87: 4984-4990

29. Caramelli E, Strippoli P, Di Giacomi T, Tietz C, Carinci P, Pasquali R (2001) Lack of mutations of type 1 11betahydroxysteroid dehydrogenase gene in patients with abdominal obesity. Endocr Res 27:47-61

30. Quervain DJ de, Poirier R, Wollmer MA et al. (2004) Glucocorticoid-related genetic susceptibility for Alzheimer's disease. Hum Mol Genet 13:47-52

31. Draper N, Walker EA, Bujalska IJ et al. (2003) Mutations in the genes encoding 11beta-hydroxysteroid dehydrogenase type 1 and hexose-6-phosphate dehydrogenase interact to cause cortisone reductase deficiency. Nat Genet 34:434-439

32. Duplomb L, Lee Y, Wang MY et al. (2004) Increased expression and activity of 11beta-HSD-1 in diabetic islets and prevention with troglitazone. Biochem Biophys Res Commun 313:594-599

33. Liu ML, Olson AL, Edgington NP, Moye-Rowley WS, Pessin JE (1994) Myocyte enhancer factor 2 (MEF2) binding site is essential for $\mathrm{C} 2 \mathrm{C} 12$ myotube-specific expression of the rat GLUT4/muscle-adipose facilitative glucose transporter gene. J Biol Chem 269:28514-28521

34. Watada H, Kajimoto Y, Kaneto H et al. (1996) Involvement of the homeodomain-containing transcription factor PDX-1 in islet amyloid polypeptide gene transcription. Biochem Biophys Res Commun 229:746-751

35. Ornatsky OI, McDermott JC (1996) MEF2 protein expression, DNA binding specificity and complex composition, and transcriptional activity in muscle and non-muscle cells. J Biol Chem 271:24927-24933

36. Thai MV, Guruswamy S, Cao KT, Pessin JE, Olson AL (1998) Myocyte enhancer factor 2 (MEF2)-binding site is required for GLUT4 gene expression in transgenic mice. Regulation of MEF2 DNA binding activity in insulin-deficient diabetes. J Biol Chem 273:14285-14292

37. Mora S, Yang C, Ryder JW, Boeglin D, Pessin JE (2001) The MEF2A and MEF2D isoforms are differentially regulated in muscle and adipose tissue during states of insulin deficiency. Endocrinology 142:1999-2004

38. Jonsson J, Carlsson L, Edlund T, Edlund H (1994) Insulinpromoter-factor 1 is required for pancreas development in mice. Nature 371:606-609

39. Ohlsson H, Karlsson K, Edlund T (1993) IPF1, a homeodomain-containing transactivator of the insulin gene. EMBO J 12:4251-4259 